0 uso argumentativo da pressuposição linguística em textos jornalísticos: um estudo sobre editoriais

The argumentative use of the linguistic presupposition in journalistic texts: a study about editorials

Marco Antônio Rosa MACHADO (UEG) machadorvd@yahoo.com.br

Drielle Lorane de Souza MENDONÇA (UEG) drielleloranes@hotmail.com

Recebido em: 31 de jan. de 2018. Aceito em: 31 de jul. de 2018.
MACHADO, Marco Antônio Rosa;

MENDONÇA, Drielle Lorane de Souza.

O uso argumentativo da pressuposição

linguística em textos jornalísticos: um estudo sobre editoriais. Entrepalavras Fortaleza, v. 8, n. 2, p. 174-195, maio/ ago. 2018.

Resumo: Este artigo tem como objetivo apresentar uma análise do uso argumentativo da pressuposição em dois editoriais jornalísticos da Folha de S. Paulo online, buscando associar o uso desse tipo de implícito às suas contribuições para a construção de sentido do texto e da argumentação. A pressuposição é considerada aqui como um tipo de implícito com expressivo papel discursivo-argumentativo, e como um fenômeno cujo conhecimento é de extrema importância para o domínio da capacidade de compreensão dos possíveis sentidos de um discurso. A escolha do gênero textual editorial possibilitou mostrar o funcionamento da pressuposição em situações reais de uso e estabelecer comparações entre o que é colocado pelos teóricos da área e exemplos reais. A partir de nossas análises e reflexões, percebemos, especificamente nos editoriais, um grande número de ocorrências do fenômeno estudado, em relação aos demais tipos de acionadores de pressupostos, que pouco ocorrem. A ponderação que fazemos sobre esse uso é que, a fim de ampliar os recursos argumentativos e fortalecer os existentes, os autores lançam mão dos pressupostos.

Palavras-chave: Pressuposição linguística. Semântica. Implícitos. 


\begin{abstract}
This article aims to present an analysis of the argumentative use of the presupposition in two journalistic editorials of Folha de S. Paulo online, seeking to associate the use of this type of implicit to its contributions to the construction of meaning of text and argumentation. The presupposition is here considered as an implicit type with expressive discursive-argumentative role, and as a phenomenon whose knowledge is of extreme importance for the mastery of comprehension ability of the possible meanings of a discourse. The choice of the editorial genre made it possible to show the functioning of the presupposition in real situations of use and to establish comparisons between what is put by the area theorists with real examples. From our analysis and reflections, we noticed, specifically in the editorials, a large number of occurrences of the phenomenon studied, related to the many types of presupposition triggers, which occurs not very often. The consideration we make about this use is that, in order to broaden the argumentative resources and strengthen the existing ones, the authors make use of the assumptions.
\end{abstract}

Keywords: Linguistic presupposition. Semantics. Implicits.

\title{
Introdução
}

O objeto de estudo deste trabalho é a pressuposição, considerada aqui como um tipo de conteúdo linguístico que se apresenta de forma implícita nos enunciados (DUCROT, 1977, 1984; LEVINSON, 2007). O implícito pode se manifestar mais livremente, apenas a partir do contexto, ou pode ter sua manifestação mais restrita ao elemento linguístico no qual se ancora. É nesse segundo caso que se inclui a pressuposição linguística na acepção que usamos neste trabalho, já que a consideramos como um fenômeno vinculado à interpretação de certos itens ou construções linguísticas. A pressuposição também é considerada aqui como um tipo de conteúdo que é revelado a partir de certo grau de reflexão do interlocutor sobre o que foi dito pelo locutor, caracterizando-se então como um tipo de inferência, ou seja, como uma informação semântica não explícita que é obtida a partir de informações dadas pelos elementos linguísticos presentes em uma frase e/ou texto (LEVINSON, 2007).

As teorias que estudam o fenômeno da pressuposição propõem diversas abordagens e ainda é questão polêmica definir em qual campo ela melhor se situa: no da semântica ou no da pragmática. Este trabalho não tem a pretensão de resolver essa questão nem ela é foco de nossa pesquisa, por essa razão não aprofundamos essa discussão. Por considerarmos apenas o significado linguístico (mais ligado ao aspecto literal da língua e objeto de estudo da Semântica) e não tratarmos da relação do contexto com a pressuposição, o que demandaria uma abordagem que considerasse as teorias pragmáticas para o estudo do fenômeno (cf. MOURA, 2006), optamos pelo tratamento semântico da pressuposição, mais adequado aos nossos objetivos. 
v. 8 (2)

$174-195$

mai/ago 2018

Ao se pensar nas relações humanas estabelecidas por meio da linguagem, e mais especificamente através dos textos argumentativos, o estudo da pressuposição linguística torna-se relevante e com potencial de agregar conhecimento para as discussões sobre o significado e o sentido na língua. Dentre outras capacidades, o uso da pressuposição suaviza, manipula, retira de contestação e imprime novos sentidos sobre o que foi dito ou até mesmo isenta o locutor de algumas afirmações. Quando colocado dessa maneira, é evidente a necessidade de estudo desse fenômeno, já que inferir sentidos e entender o que é implicitado é fundamental na leitura crítica de um texto.

Além disso, as investigações acerca do uso desse mecanismo a partir de textos reais ou de corpus de pesquisa são raros, e, comumente, os trabalhos teóricos a que tivemos acesso no decorrer dessa investigação não tomam como objeto de estudo os efeitos argumentativos dos pressupostos em textos mais longos.

Nesse sentido, este artigo tem por objetivo analisar o uso argumentativo da pressuposição em dois textos jornalísticos (editoriais), veiculados pela Folha de S. Paulo online entre os dias $1^{\circ}$ e 3 de outubro de 2017, buscando associar o uso desse tipo de implícito às suas contribuições para a construção de sentido do texto.

O artigo está disposto em seções que se iniciam com uma apresentação das teorias que o fundamentam, seguida da apresentação dos procedimentos metodológicos adotados. Partimos, então, para a análise dos dois textos jornalísticos e por fim são apresentadas as conclusões a que chegamos com nossa pesquisa.

\section{A noção de pressuposição}

Frege (1892 /2009) foi um dos primeiros estudiosos a chamar a atenção para a pressuposição. Ele observou que algumas sentenças revelam um tipo de conteúdo que não é afetado quando sentenças de tipos específicos são negadas, colocadas em forma interrogativa ou mesmo combinadas com uma condicional que antecede outra sentença, como ilustram os exemplos a seguir.

\section{(01)}

a. Sentença: O homem que inventou o plástico vendeu sua patente.

b. Negação: O homem que inventou o plástico não vendeu sua patente. 
c. Interrogação: O homem que inventou o plástico não vendeu sua patente?

d. Condicional: Se o homem que inventou o plástico vendeu sua patente, ele deve estar rico ${ }^{1}$.

De acordo com Moura (2006), essas sentenças, ao serem analisadas, nos mostram dois níveis de informações; e é o segundo nível dessas informações que constitui esse conteúdo não afetado, como postulou Frege. O primeiro nível seria, segundo Moura (2006), o responsável pelas informações num plano literal, em que alguma coisa é claramente afirmada. Já o segundo nível nos leva a considerar "outras informações que não são afirmadas literalmente, mas inferidas a partir dessas sentenças" (MOURA, 2006, p. 13).

Ducrot (1977) denomina as informações contidas nesse primeiro nível de conteúdo posto, e as informações contidas nesse segundo nível de conteúdo pressuposto. Essas informações, mesmo que em segundo nível, se manifestam de forma inscrita na língua, como aponta Ducrot. Para o autor,

o fenômeno da pressuposição parece estar em estreita relação com as construções sintáticas gerais - o que fornece uma primeira razão para tratá-lo como componente linguístico onde, evidentemente, deveria ser descrito o valor semântico dessas construções (DUCROT, 1984, p. 19).

A escolha do falante de inserir informações nesse segundo nível se deve, conforme Ducrot (1977), à recorrente necessidade de "ao mesmo tempo, dizer certas coisas e de poder fazer como se não as tivéssemos dito; ou de dizê-las, mas de tal forma que possamos recusar a responsabilidade de tê-las dito" (p. 13). Cabral (2010) afirma que existem, também, situações em que não nos interessa dizer tudo abertamente e que justificam o uso dos implícitos, como "um impedimento em relação a determinada informação, o medo de ofender o interlocutor ou gerar um constrangimento, um tabu dentro da comunidade de que participamos, entre outros motivos" (p. 60).

Para Ducrot (1977), existem pelo menos duas origens teoricamente distintas para a necessidade do implícito nas relações sociais. A primeira diz respeito ao fato de que em toda coletividade há um conjunto de tabus linguísticos. O que não significa apenas a existência de palavras que não podem ou não devem ser pronunciadas, trata-se de temas inteiros proibidos

${ }^{1}$ Perceba que a existência de alguém responsável pela invenção do plástico permanece em qualquer uma das colocações. 
v. $8(2)$

$174-195$

mai/ago 2018

e protegidos pelo que o autor chama de "lei do silêncio". Ele aponta que "há formas de atividade, sentimento, acontecimentos, de que não se fala".

Há também, conforme exposto por Ducrot:

para cada locutor, em cada situação particular, diferentes tipos de informação que ele não tem o direito de dar, não porque elas sejam em si mesmas objeto de alguma proibição, mas porque o ato de dá-las constituiria uma atitude considerada repreensível (DUCROT, 1977, p. 13).

Isso se daria pelos possíveis efeitos que determinadas afirmações causariam no interlocutor. No entanto, ainda assim:

pode haver fortes razões para falar de coisas que tais, torna-se necessário ter disposição de modos implícitos de expressão, que permitam deixar entender sem acarretar a responsabilidade de ter dito (DUCROT, 1977, p. 14).

Assim, salienta-se a ideia de que o locutor trabalha a partir do recurso existente na língua, favorecendo então a ideia da pressuposição linguística.

A segunda origem do implícito, segundo Ducrot (1977), diz respeito ao fato de que "toda informação explicitada torna-se, por isso mesmo, um tema de discussões possíveis" (p. 14) Assim, as informações declaradas explicitamente são abertas às críticas e aos questionamentos, e, visando evitar confrontos, "procuramos formas de dizer que não exponham o conteúdo defendido à contestação" (CABRAL, 2010, p. 60).

É nesse sentido que Cabral (2010), retomando Ducrot (1987), sustenta que a pressuposição parece aprisionar o interlocutor num universo intelectual que ele não escolheu, mas que se apresenta como coextensivo ao diálogo, tirando-lhe a possibilidade de negá-lo ou questioná-lo. É também por essa razão que Maingueneau (1996 apud CABRAL, 2010) afirma que os pressupostos oferecem a possibilidade de serem usados para finalidades manipuladoras, um dos motivos para lhe conferir lugar de destaque nas interações verbais.

Sendo assim, o conteúdo semântico da pressuposição não é objeto direto de declaração e de comprometimento do falante, mas algo dado como uma espécie de conhecimento dado, partilhado pelos participantes do ato comunicativo e inscrito no enunciado, mas que precisa ser depreendido dele. Nesse sentido, Ducrot aponta que pressupor é, também, "situar o diálogo na hipótese de que ele² já soubesse" (1977, p. 77).

\footnotetext{
${ }^{2}$ Nesse ponto, Ducrot refere-se ao ouvinte.
} 
Os testes

Os critérios, ou testes, propostos para identificação de pressupostos foram inicialmente formulados por Frege e posteriormente trabalhados por outros teóricos, são eles: a regra da negação e a regra da interrogação.

A regra da negação diz respeito a uma característica básica da pressuposição: a negação não afeta os pressupostos de um enunciado. Vejamos isso a partir deste exemplo:

(2) "Meu amigo parou de escrever" (SOUZA, 2000, p. 20).

O pressuposto aqui é que o amigo escrevia. Na negativa:

(3) Meu amigo não deixou de escrever.

O fato de ele escrever (no passado) não mudou.

Para Souza (2000, p.21), "[...] quando uma informação não é afetada pela negação numa sentença, é sinal de que tal informação não fora assertada, mas, segundo o conceito que ele próprio lançou, pressuposta" (p. 21). Segundo o autor, o teste da negação é um dos critérios mais fortes e seguros para análise da pressuposição. ${ }^{3}$

Já a regra da interrogação diz respeito ao fato de a pressuposição também não se alterar a quando a frase é passada para a interrogativa. Vejamos a mesma frase agora de forma interrogativa:

(4) "Meu amigo parou de escrever?" (SOUZA, 2000, p.23)

O fato de que ele escrevia permanece.

Conforme Souza (2000), a interrogação apresenta problemas enquanto teste para a detecção dos pressupostos, já que há sentenças que não são passíveis de se apresentarem na forma interrogativa. É o que ocorre com sentenças imperativas, que, por apresentarem natureza diferente, não podem ser submetidas à interrogação.

Cançado (2008) propõe que a condicional também poderia ser considerada um tipo de teste. Segundo esse teste, ao adicionar uma condicional na sentença (e uma continuação a essa sentença para garantir seu sentido) a pressuposição permanece:

3 Existe, segundo Souza (2000), a possibilidade de se negar o pressuposto que ocorre exclusivamente se ele for transposto para o nível do sentido explícito, independente das estruturas linguísticas acionadoras de pressuposto em questão. 
V. 8 (2)

$174-195$

mai/ago 2018

(5) Se meu amigo parou de escrever, a sociedade deve ficar de luto.

Como na negação e na interrogação, o fato de o amigo escrever continua pressuposto na sentença.

\section{Acionadores de pressupostos}

De acordo com Souza (2000), a pressuposição é sempre introduzida, na linguagem, por itens lexicais ou estruturas gramaticais específicos, chamados aqui de acionadores de pressupostos. Esses acionadores de pressupostos são elementos que formam um grande grupo, abrangendo "o emprego dos tempos e formas verbais, a presença de certos advérbios e construções sintáticas, etc." (SOUZA, 2000, p. 20).

A lista de acionadores de pressupostos conhecidos é extensa e não nos deteremos nessa discussão, pois isso não é o foco de nosso trabalho. Levinson 4 (2007, p. 225-240) menciona 13 tipos, selecionados entre 31 que o autor mapeou na bibliografia sobre o tema, entre os quais mencionamos, a seguir, alguns como ponto de partida para nossa reflexão.

Seguem exemplos de acionadores de pressupostos:

a. Descrições definidas: João viu o homem com duas cabeças ${ }^{5}$ >> pp.: Existe um homem com duas cabeças.

b. Verbos factivos: Pedro soube que ganhou o prêmio >> pp.: Pedro ganhou o prêmio.

c. Verbos implicativos: João conseguiu abrir a porta >> pp.: João tentou abrir a porta.

d. Verbos de mudança de estado: João deixou de fumar. >> pp.: João fumava.

e. Palavras ou expressões iterativas: O disco voador apareceu de novo >> pp.: O disco voador tinha aparecido antes.

f. Expressões temporais: Maria desmaiou depois de encontrar João >> pp.: Maria encontrou João.

g. Sentenças clivadas: Não foi o João que beijou Maria >> pp. Alguém beijou Maria.

\footnotetext{
4 Para aprofundar essa questão, confira a bibliografia apresentada por Levinson (2007).

${ }^{5}$ Exemplos dos itens a) - g) foram retirados de: MOURA, H. M. de M. Significação e contexto: uma introdução a questões de semântica e pragmática. 3. ed. Florianópolis: Insular, 2006.
} 
h. Expressões factivas ${ }^{6}$ : Clarice estava contente com o presente que ganhou. >> pp. Clarice ganhou um presente.

i. Comparações e contrastes: ${ }^{7}$ Carol é uma linguista melhor do que Barbara >> pp. Barbara é linguista.

j. Clivagens implícitas com constituintes enfatizados: A Linguística não foi inventada por Chomsky >> pp. Alguém inventou a Linguística.

k. Orações relativas não restritivas: Os proto-harpianos, que floresceram entre 2800-2650 a.C., foram/ não foram grandes construtores de templos. >> pp. Os protoharpianos floresceram entre 2800-2650 a.C.

1. Condicionais contra factuais: Se o aviso ao menos dissesse "campo minado" em inglês, além de galês, teríamos; nunca teríamos perdido o pobre Llewellyn. >> pp. O aviso não dizia campo minado em inglês.

m. Interrogações: Quem é o professor de Linguística no MIT? >> pp. Alguém é professor de Linguística no MIT.

n. Verbos de julgamento: Ian criticou/ não criticou Agatha por fugir $>>$ pp. (Ian pensa que) Agatha fugiu.

Descrições definidas

Dentre os acionadores de pressupostos observados, as descrições definidas, ou nominalizações, são destaque por serem o tipo de acionador mais recorrente em nosso corpus.

De acordo com Ducrot (1977, p. 232), "chamam-se frequentemente 'referenciais' as expressões que permitem ao locutor designar, para o destinatário, um ou mais objetos particulares do universo do discurso [...]". Incluídas nessas expressões, estão "os grupos nominais, precedidos do artigo definido, ou seja, segundo a expressão de Russel, as 'descrições definidas'” (DUCROT, 1977, p. 232). As descrições definidas constituem, assim, uma construção linguística, formada por um sintagma nominal. De acordo com Ducrot, são raros os casos em que as descrições definidas são empregadas apenas com função referencial, "como simples meio de individualizar um objeto"

6 Exemplo do item h) foi retirado de: OLIVEIRA, Iracelane Ferreira da Silva. Pressuposição: da sentença ao texto. 2014. 102 f. Dissertação (Mestrado em Linguística e ensino) - Universidade Federal da Paraíba, João Pessoa, 2014.

7 Exemplos dos itens i) - n) foram retirados de: LEVINSON, Stephen C. Pragmática. São Paulo: Martins Fontes, 2007. (Original: 1983). 
v. $8(2)$

$174-195$ mai/ago 2018
(1977, p. 234). Em contrapartida, elas apresentam um comportamento de forma quase constante indicações existenciais ${ }^{8}$ (DUCROT, 1977).

Essas indicações existenciais possibilitam às descrições definidas se incluírem no grupo dos acionadores de pressupostos, veiculando um pressuposto específico: a pressuposição de existência. Para Ducrot (1977), essa pressuposição de existência é baseada na designação. No entanto, o sentido de designação aqui adotado não remete ao seu sentido tradicional de apontar alguma coisa. Para o autor, designar algo significa "'tomar esse algo como existente', 'fazer de sua existência o fundamento do discurso', e finalmente, 'pressupor que esse algo exista'" (1977, p. 247).

Tendo as características mencionadas, a nominalização é, então, um potente recurso argumentativo já que apresenta a informação como conhecimento público ao pressupor a existência daquilo que se designa, de forma que não se pode discuti-la ou negá-la (OLÍMPIO, 2006). Trata-se de uma característica também compartilhada pelos demais tipos de acionadores. Tendo esse traço, o locutor, ao pressupor uma informação, consegue desviar o foco dessa informação para outra, configurando-se uma das fortes razões que levam ao uso dos implícitos. Também ocorre, por algum motivo, de o interlocutor não pretender se responsabilizar por certa colocação (que daria margem a discussões) o que caracteriza um motivo plausível para que se faça uso das descrições definidas.

Ducrot, referindo-se às particularidades das descrições definidas, afirma ainda que a "existência de semelhante pressuposto exprime a propriedade, totalmente específica das línguas naturais, de que a palavra institui, no momento em que é enunciada, o universo de que fala" (1977, p. 250), retomando assim a ligação entre as descrições definidas e o pressuposto de existência.

\section{Procedimentos metodológicos}

Para as análises que empreendemos neste trabalho, adotamos uma abordagem qualitativa, com perspectiva descritiva e interpretativa, a partir da seleção de dois textos que foram escolhidos do seguinte modo: inicialmente, havíamos selecionado seis editoriais da Folha de S. Paulo, publicados entre os dias $1^{\circ}$ e 3 de outubro de 2017, para comporem o corpus.

${ }^{8}$ Ducrot convenciona chamar "às ideias de existência e unicidade veiculadas pelas descrições definidas" de indicações existenciais (1977, p. 233). 
A partir de uma busca prévia por itens linguísticos específicos que acionam pressupostos, baseado em Levinson (2007), constatamos uma baixa ocorrência, e desse modo a quantidade de textos selecionados seria insuficiente. A fim de aumentar o corpus e obter material suficiente para a análise, foram escolhidos posteriormente mais quatorze textos, publicados entre os dias 4 e 10 de outubro de 2017, totalizando vinte editoriais. Entretanto, durante as observações desses editoriais, percebemos que um tipo específico de acionador de pressuposto, as "descrições definidas" (também classificadas como indicadoras de "pressuposto existencial"), ainda não haviam sido quantificadas. Ao investigar as ocorrências das descrições definidas, notamos uma recorrência bastante elevada, e consideramos interessante observálas. Por ser um número grande de manifestações e levando em conta o espaço pequeno deste artigo, optamos por nos dedicar à análise de apenas dois textos, que são os que passam a compor o corpus analisado e apresentado a seguir: "A um ano do pleito" e "Direção errada".

Os excertos obtidos desses dois textos são analisados qualitativamente, de forma a evidenciar tendências de uso de itens e construções linguísticas que acionam pressupostos bem como as implicações desse uso. Os excertos também são observados quantitativamente a fim de estabelecer se as ocorrências de pressupostos são frequentes em editoriais jornalísticos. A escolha desse gênero textual deveu-se ao nosso interesse em restringir a investigação à esfera jornalística e a um gênero argumentativo de ampla circulação em nossa cultura.

\section{Análise do corpus}

Como já mencionado anteriormente, analisamos o uso da pressuposição linguística em dois editoriais da Folha de S. Paulo, disponíveis online, na internet. Dessa forma, cabe aqui um breve comentário sobre esse gênero e sobre suas relações com recursos linguísticos.

Lage (2006) afirma que é papel do texto jornalístico transmitir informações de maneira imparcial, com foco nos fatos, e sem demonstrar opiniões. Por essa razão, indícios de opinião ou de pontos de vista costumam ser veiculados nas entrelinhas, ainda que possam ser marcados linguisticamente. No entanto, essa consideração só se aplica de forma plena aos gêneros informativos (notícia e reportagem). 
v. $8(2)$

$174-195$ mai/ago 2018

O editorial, por pertencer aos gêneros opinativos, escapa dessa necessidade de camuflar opiniões (cf. MELO, 1994), a não ser no que se refere aos posicionamentos políticos e/ou ideológicos, para os quais os textos jornalísticos costumam apresentar uma pretensa imparcialidade, com opiniões supostamente neutras, com raras exceções.

A pressuposição se torna objeto de estudo pertinente para os estudos da linguagem, afinal, ao oferecer a possibilidade de não contestação/questionamento das informações pressupostas, as opiniões veiculadas por meio das pressuposições presentes em um texto ganham estatuto de uma espécie de fato inconteste, o que reforça a argumentatividade, favorecendo, principalmente, o texto jornalístico opinativo. Poder dizer o que se pretende, sem fazê-lo de forma explícita, é um importante recurso para o texto jornalístico fortalecer sua argumentatividade, sem perder explicitamente sua imparcialidade política ou ideológica, no caso do editorial.

Para Oliveira (2014), no momento em que se coloca a informação pressuposta à margem do discurso, o locutor passa a possuir, entre outras, a vantagem de não ser atacado ou responsabilizado por isso, levando-se em consideração que o objeto de julgamento do leitor deve se referir ao que é explícito, e não ao que se encontra à margem. Por ser a linguagem subjetiva por natureza, conforme Ducrot (apud OLIVEIRA, 2014), e dessa forma veicular informações carregadas de intenções, é que se possibilita o manejo e existência desses recursos linguísticos.

Nesse sentido, o objetivo desta seção é discorrer sobre os efeitos argumentativos causados pelo uso da pressuposição para veicular determinada informação. É necessário ir além de apenas identificar o pressuposto e seu acionador (o que constitui o tipo de análise mais comumente encontrado nos trabalhos que consultamos).

Nos dois textos analisados, o número absoluto de ocorrências de acionadores de pressupostos foi relativamente alto (aproximadamente 40), somados os diversos tipos mencionados em 1.2. No entanto, em muitos casos, a carga argumentativa é quase nula, motivo pelo qual julgamos desnecessário para nossos propósitos comentar todas as ocorrências. Assim, analisamos as manifestações que julgamos mais pertinentes em relação aos objetivos deste trabalho. Os excertos são dispostos na análise de forma a preservar o microcontexto em que cada um está situado.

Levando em conta essas considerações, passamos a apresentar como o uso desse recurso linguístico se dá em textos reais. 
Texto 1:

\begin{abstract}
A um ano do pleito
Pesquisas de intenção de voto realizadas um ano antes da data do pleito devem ser lidas com cautela. Cuidados e ressalvas são ainda mais recomendáveis tratando-se da próxima disputa presidencial.

O quadro de candidatos ainda não se definiu, nem as reais possibilidades da miríade de nomes em cena. 0 país atravessa um período de instabilidade política e mal superou a brutal recessão econômica; sobressaltos causados por episódios de corrupção atingem políticos de diferentes partidos e inclinações ideológicas.

É natural que nesse cenário instável e especulativo apareçam com destaque políticos com imagem já consolidada no imaginário do eleitorado - e que surjam, em contrapartida, alguns franco-atiradores.
\end{abstract}

Não surpreende, portanto, que o ex-presidente Luiz Inácio Lula da Silva (PT) lidere os cenários eleitorais apresentados pela pesquisa Datafolha que vem à luz neste domingo $\left(1^{\circ}\right)$. Tampouco que Marina Silva (Rede) fique em vantagem quando o nome do petistá é retirado da lista de postulantes.

São nomes que, por razões diversas, se mantêm vivos na memória de parte significativa da população. Lúla, cuja candidatura é cada vez mais incerta, por ter governado em época de vacas gordas; Marina, pela presença nos últimos dois pleitos - e por não ter sido envolvida em escândalos.

O petista, contudo, tem a maior rejeição entre todos os candidatos. Somam $42 \%$ os que dizem que não votariam em Lula de jeito nenhum, percentual bem acima dos 26\% que descartam Marina.

Além de restrições partidárias, decerto contribui para o repúdio ao ex-presidente a importância atribuída pelos entrevistados à ficha limpa dos postulantes.

O vice-campeão em rejeição, com 33\%, é Jair Bolsonaro (PSC), o mais cotado dos franco-atiradores. A elevada intenção de voto no deputado, que defende teses de conservadorismo tosco, pode ser em parte explicada pela atmosfera de repulsa aos políticos e pela ausência de uma candidatura de centro-direita mais definida.

O governador de São Paulo, Geraldo Alckmin, um dos nomes que poderiam ocupar essa faixa, ainda disputa com o prefeito paulistano João Doria a candidatura do PSDB. Nos diversos cenários, ambos aparecem em posição equivalente, sem superar 10\% das intenções.

É plausível que candidaturas moderadas venham a conquistar terreno na disputa. Afinal, parte relevante do eleitorado evita os extremos do espectro ideológico, aproximando-se do centro. Se confirmada, a expectativa de aceleração da economia no próximo ano também concorre, em tese ao menos, para esvaziar radicalismos.

Texto disponível em: <http://www1.folha.uol.com.br/opiniao/2017/10/1923239-aum-ano-do-pleito.shtml>. Acesso em: 10 out. 2016. 
v. 8 (2)

$174-195$

mai/ago 2018

Análise

Tendo em vista as discussões teóricas que fizemos até agora, passamos a apresentar as análises que fizemos com o objetivo de mostrar como a pressuposição é usada em textos reais, mais especificamente em editoriais jornalísticos. Como já dito, apenas algumas das manifestações que se caracterizam como pressuposição são analisadas aqui, já que nem todas apresentam significância para nossos objetivos. O conteúdo posto das proposições será apresentado em (X) e o conteúdo pressuposto em (Xa) ${ }^{9}$, sendo $\mathrm{X}$ correspondente ao número da pressuposição de acordo com sua ordem de ocorrência nos textos. Logo após a apresentação dos excertos, mostramos as inferências que desenvolvemos a partir destes, sendo por vezes relacionadas apenas com o trecho em evidência e em alguns casos relacionadas aos sentidos estabelecidos em todo o texto. Dito isso, iniciamos a exposição dos dados e das inferências relativas ao texto 1, que estão destacadas em cinza no texto:

(6) O país atravessa um período de instabilidade política e mal superou a brutal recessão econômica;

(6a) pp. O país passou por uma brutal recessão econômica.

(6b) pp. Existiu uma brutal recessão econômica.

Os pressupostos (6a) e (6b), inscritos em (6), são acionados pelo verbo "superou" e pela construção "a brutal recessão econômica", respectivamente. Para o jornal, não é conveniente afirmar e explicitar essa informação, dessa forma, ao colocá-la como fato dado ela parece ser comum e conhecida por todos, isentando o veículo de polêmicas e discussões sobre o assunto. A construção da sentença já mostra que o foco que o jornal deseja manter é a continuidade do discurso em torno da instabilidade política, deixando a questão econômica em segundo plano. Assim, não cabe ao leitor questionar se o país passou por uma brutal recessão econômica ou não. Na verdade, a construção deixa pouca margem para o fato de a recessão ter ficado no passado. Em "mal superou", o efeito negativo acrescido por "mal" implica "superou" (verbo de mudança de estado), uma implicitação dupla, aprisionando o leitor em um universo intelectual não escolhido por ele, que é uma característica da pressuposição, levantada por Ducrot e neste texto já abordada. Desse modo, o efeito de sentido causado pela pressuposição constitui a parte mais importante da mensagem.

${ }_{9}$ Caso ocorra mais de uma pressuposição no mesmo excerto, elas serão indicadas por (Xb) e assim sucessivamente. 
(7) É natural que nesse cenário instável e especulativo apareçam com destaque $[\ldots]$

(7a) pp. O cenário é instável e especulativo.

Mesmo sem focar explicitamente na opinião de que o cenário é instável e especulativo, essa informação é claramente percebida. Tratase de uma informação colocada à margem, e dessa forma um diálogo não prosseguiria tendo-a como foco. Assim, a construção dificulta questionar se de fato esse cenário é instável e especulativo, fechando o assunto para o diálogo.

(8) Não surpreende, portanto, que o ex-presidente Luiz Inácio Lula da Silva (PT) lidere os cenários eleitorais apresentados pela pesquisa Datafolha que vem à luz neste domingo $\left(1^{\circ}\right)$.

(9) Tampouco que Marina Silva (Rede) fique em vantagem quando o nome do petista é retirado da lista de postulantes.

(8a) pp. Lula lidera.

(9a) pp. Quando o nome de Lula é retirado Marina fica em vantagem.

É implicitamente que a informação da liderança de Lula é dada, bem como a informação da vantagem de Marina, quando se tira o nome de Lula de cena. Isso de certa forma suaviza o fato de que Lula ocupa a liderança e encaminha o leitor a atentar para as razões de essa informação não ser uma surpresa. Possivelmente essa implicitação foi feita para dar a entender que o texto não está favorecendo ou desfavorecendo nenhum dos possíveis candidatos, mas essa tentativa de ser imparcial é falsa já que a afirmação desfavorece/desacredita tanto Luiz Inácio Lula da Silva quanto Marina Silva, mas principalmente o petista.

(10) Além de restrições partidárias, decerto contribui para $\underline{0}$ repúdio ao ex-presidente a importância atribuída pelos entrevistados à ficha limpa dos postulantes.

(10a) pp. Existe um repúdio ao ex-presidente

Ao designar o repúdio ao ex-presidente, o autor admite que esse repúdio existe. No entanto, asseverar a existência desse repúdio abertamente seria polêmico e alvo de contestações. Ao colocar essa 
v. $8(2)$

$174-195$

mai/ago 2018

informação à margem do discurso, ela ganha maior naturalidade e é tida como conteúdo compartilhado pelo leitor, eximindo assim o autor da responsabilidade pelo próprio dizer. Mas novamente o leitor é aprisionado em um universo em que, ao aceitar a sentença toda, não há como negar que o ex-presidente é repudiado. Dado que a informação de repúdio aqui é implícita, chama atenção que em (11) o contrário ocorre, ao se referir à rejeição de Jair Bolsonaro.

(11) O vice-campeão em rejeição, com 33\%, é Jair Bolsonaro (PSC), o mais cotado dos franco-atiradores.

(11a) pp. Existe um grupo de franco-atiradores.

Segundo o excerto, além de rejeitado, Jair Bolsonaro pertence ao grupo dos franco-atiradores, do qual é o mais cotado. Dessa forma, é pressuposto que existe um grupo de franco-atiradores, o qual possivelmente é composto por candidatos que estão "arriscando" (já que um grupo de pessoas, a maioria sem expressividade política alguma, surgiu como possíveis candidatos para as eleições presidenciais de 2018).

(12) A elevada intenção de voto no deputado, que defende teses de conservadorismo tosco [...]

(12a) pp. Existe uma elevada intenção de voto no deputado.

Em (12) temos asseverado que o deputado apresenta uma elevada intenção de voto. A informação que precede a sentença (12) é a de que o candidato é rejeitado, mas ela não exclui a pressuposição de existência de sua elevada intenção de voto. Em (8) e (9), as informações sobre as posições dos candidatos nas pesquisas de intenção de voto são implicitadas, assim como em (12). Note que, no caso de Lula, as informações sobre as intenções de voto antecedem as informações sobre o repúdio ao ex-presidente. No caso de Bolsonaro, o que ocorre é o inverso. A rejeição é apresentada antes das intenções de voto. Assim, o autor diminui a credibilidade do deputado. Os possíveis candidatos mencionados no texto são, de uma forma ou de outra, diminuídos. A intencionalidade por trás dessa diminuição é incerta, mas aponta para o desejo de construir uma aparente imparcialidade. 
(13) A atmosfera de repulsa aos políticos e pela ausência de uma candidatura de centro-direita mais definida.

(13a) pp. Existe uma atmosfera de repulsa aos políticos.

Não apenas Lula e Bolsonaro são repudiados e rejeitados, existe uma atmosfera de repulsa aos políticos como um todo. Isso é colocado para o leitor como um fato. O povo rejeita os políticos. A possibilidade de discordar da afirmação é excluída, enquanto ela se mantém pressuposta.

\section{Breves considerações}

Percebamos, a partir da análise dos pressupostos do texto 1 , que questões que poderiam gerar conflitos constantemente não são evidenciadas e sim implicitadas. Informações como a situação econômica do Brasil, o cenário político atual e futuro, a relação da população com os possíveis candidatos e a imagem tecida desses têm seus julgamentos implicitados. Colocar o texto dessa forma contribui para a construção da argumentação. Cabe aqui, então, a afirmação de Koch (2008), que declara que argumentar é "orientar o discurso no sentido de determinadas conclusões" (p. 17). Nessa perspectiva, percebemos, a partir dos exemplos analisados, que as pressuposições contribuem para o aspecto argumentativo do discurso. 
V. 8 (2) $174-195$ mai/ago 2018

Texto 2:

\section{Direção errada}

Os atores relevantes já entenderam que não existe solução única para tirar o ensino público do atoleiro em que se encontra. Sair do marasmo pessimista exige um conjunto de ações que vai de adotar uma base curricular nacional até valorizar a carreira de professor e cobrar resultados concretos.

Também há consenso quanto ao papel central do diretor de escola. A ele ou a ela compete liderar o corpo docente na melhora paulatina do processo de aprendizado e gerir os recursos disponíveis para garantir as condições materiais necessárias, de banheiros limpos a computadores conectados.

O desempenho desse profissional será tanto melhor quanto mais apurada sua qualificação, no aspecto administrativo e pedagógico. A forma tradicional de sua escolha em escolas municipais e estaduais, no entanto, conspira contra isso.

Dados obtidos por esta Folha a partir de questionário aplicado em 2015 pelo Ministério da Educação a 55 mil diretores apontam que 45\% deles chegam ao cargo por mera indicação. Embora as respostas não detalhem motivos, é de supor que abundem critérios políticos.

Essa é a forma mais comum nos Estados menos desenvolvidos do Norte e do Nordeste. Amapá e Maranhão, por exemplo, têm mais de $80 \%$ dos diretores designados assim. Mas há exceçôes, como o Acre, onde apenas $11 \%$ deles dirigem escolas por escolha dos superiores.

Do contingente não escolhido por concurso ou eleição local, 23\% nunca fizeram pós-graduação. Entre os que se tornaram diretores por vias que não a indicação, o grupo dos que carecem de tal qualificação encolhe para $13 \%$. E os indicados tendem a ter menos experiência administrativa e a permanecer menos tempo em cada escola.

\section{Ainda que não haja pesquisas conclusivas correlacionando a indicação do diretor com pior avaliação pedagógica, especialistas concordam que a escolha política ameaça a qualidade.}

Por outro lado, concursos podem selecionar dirigentes bem formados, mas inexperientes; já a eleição por pares ou pela comunidade abre as portas ao corporativismo e ao aparelhamento.

Se parece difícil eleger um modo uniforme para condução de diretores em todo o país, não há dúvida de que a exigência de padrões mínimos de capacitação, com provas de conhecimento, títulos e experiência prática, permitirá nomear os melhores para a função.

Nada disso bastará se não houver mais autonomia para gerir a escola e compor a equipe de professores - e se não houver recompensas conforme o desempenho.

Texto disponível em: <http://www1.folha.uol.com.br/opiniao/2017/10/1923765direcao-errada.shtml>. Acesso em: 10 out. 2016. 
Análise

O procedimento de análise aqui realizado é o mesmo realizado para o texto 1. A numeração dos excertos dá continuidade à numeração apresentada no primeiro texto.

(14) Os atores relevantes já entenderam que não existe solução única para tirar o ensino público do atoleiro em que se encontra.

(14a) pp. Existem atores relevantes

Nesse excerto, a descrição definida "os atores relevantes" realiza uma referenciação de maneira genérica, mas ainda assim pressupõe a existência dos referentes para os quais aponta. No entanto, não é possível identificar no texto quem são esses atores, ao menos não de forma segura. A existência desses atores fundamenta e tenta legitimar o que é afirmado em (14) e retomado implicitamente no decorrer de todo o texto. A situação é semelhante ao que é feito no trecho a seguir:

(15) "Ainda que não haja pesquisas conclusivas correlacionando a indicação do diretor com pior avaliação pedagógica, especialistas concordam que a escolha política ameaça a qualidade".

O uso do termo "especialistas", mesmo que omitindo o artigo, constitui uma pressuposição de existência desses "especialistas" e, baseando-se nessa pressuposição, cria-se um argumento de autoridade. Tanto em "os atores relevantes" quanto em "especialistas", a falta da figura específica a quem esses termos remetem contribui ainda mais para o não questionamento dos fatos apresentados, já que o texto não deixa claro sobre quem é o sujeito específico da informação posta que o leitor deseje questionar.

(16) [... tirar o ensino público do atoleiro em que se encontra. (16a) Existe um atoleiro

Há uma situação que se encaixa com a definição de atoleiro vivenciada pelo ensino público, no sentido metafórico do termo atoleiro. Nesse caso, é importante associar a que o termo "atoleiro" se liga 
v. $8(2)$

$174-195$

mai/ago 2018

semanticamente. Esse termo remete, comumente, a uma situação de dificuldade, à sujeira. Comparar o estado do ensino público a esse tipo de situação e estado, e fazê-lo de forma implícita, colocando a situação como fato, é diminuir o ensino público sem querer que essa afirmação seja o foco da asserção.

(17) Sair do marasmo pessimista exige um conjunto de ações que vai de adotar uma base curricular nacional até valorizar a carreira de professor e cobrar resultados concretos. [...]

(17a) pp. O ensino público vivencia um marasmo pessimista

(17b) pp. Existe um marasmo pessimista

Para sair do "marasmo pessimista", é necessário que ele primeiramente exista e que esteja ocorrendo; ao fazer referência a ele, assume-se sua existência. Apresenta-se o fato como dado, dessa forma, o autor não precisa se posicionar e fica aparentemente imparcial, como se apenas descrevesse o estado natural das coisas. Mas não é o que acontece na realidade. Além disso, o significado do termo "marasmo" é pejorativo por si só, e essa característica é reforçada pelo adjetivo "pessimista". O termo faz referência a uma estagnação, a uma mesmice, a algo paralisado e inativo. A construção, como podemos perceber, é carregada de intencionalidade, ao assumir e implicar que o leitor assuma que se vivencia esse marasmo. Só é possível questionar até que ponto é verdadeira a caracterização feita da situação do ensino, quando se transfere a informação para o nível explícito. Ainda assim, ao colocála em nível explícito, é difícil medir o quanto colocar o ensino como estagnado é um exagero.

(18) Também há consenso quanto ao papel central do diretor de escola.

(18a) pp. O diretor tem um papel central na escola.

Existe um papel central de diretor de escola. Aideia da existência desse papel é consenso entre os "atores relevantes", informação fornecida pelo uso de "também". O argumento aqui criado, além de se basear num pressuposto anterior, é completado (complementado) por um novo pressuposto. Parece-nos que afirmar a pressuposição inscrita em (18) possui um objetivo maior no texto, ou seja, esse pressuposto de existência reforça e corrobora a tese apresentada no texto. 
(19) A ele ou a ela compete liderar o corpo docente na melhora paulatina do processo de aprendizado e gerir os recursos disponíveisparagarantirascondições materiaisnecessárias, de banheiros limpos a computadores conectados.

(19a) pp. Existem recursos disponíveis para garantir as condições materiais necessárias [...]

Seria polêmico afirmar que as escolas dispõem de recursos suficientes para garantir todas as condições materiais necessárias já que muitos gestores administram escolas (ou dizem fazê-lo) em situações precárias. Dessa forma, afirmar implicitamente que esses recursos são existentes exime o responsável pela notícia de participar dessa discussão e situa o decorrer das interpretações da leitura em outro caminho.

Breves considerações

Ao tratar da educação pública no Brasil, o texto "Direção errada" apresenta os implícitos de forma a "pôr" e encaminhar as conclusões do leitor acerca da ideia de que o ensino público no Brasil está em péssima situação e não sai do lugar. Além disso, o texto não estabelece explicitamente quem são "os atores relevantes" e os "especialistas" e, ainda, usa-os como figuras importantes, e existentes, para legitimar o que o texto apresenta. Vale ressaltar que são mencionados no texto apenas quatro agentes da educação. Os agentes primários, apresentados de forma explícita, são os professores e os diretores. De forma secundária, é apresentada a "comunidade". E de forma implícita está o poder público. São esses agentes que recebem a maior parte das críticas desferidas (concebidas) no texto. A forma com que as informações implicitadas são apresentadas no editorial direciona o leitor às conclusões pretendidas pelo autor do texto.

\section{Considerações finais}

Consideramos ter abordado um estudo pertinente da pressuposição linguística em editoriais jornalísticos. A demanda pelo estudo do fenômeno da pressuposição linguística em corpus não consegue ser satisfeita senão com uma pesquisa ampla e detalhada, o que não é caso desta, já que fizemos um trabalho apenas com uma amostra restrita a dois textos. No entanto, a partir de nossas análises e reflexões, pudemos perceber que os editoriais, em específico, utilizam 
V. 8 (2)

$174-195$

mai/ago 2018

a pressuposição linguística em grande escala, mormente no que se refere às descrições definidas. A ponderação que fazemos sobre esse uso é que, sobre a pretensa imparcialidade política objetivada nos textos jornalísticos opinativos, os autores destes textos lançam mão dos implícitos para construir e fortalecer sua argumentação.

A construção de sentidos que ocorre nos textos analisados se liga diretamente aos implícitos neles presentes. É fato que, ao explicitar informações, o texto fica aberto ao diálogo e o leitor pode questionar e pôr em discussão o que é dito. No entanto, sem inferir sentidos, o leitor é obrigado a aceitar diversos fatos e situações como verdadeiros a partir de um único ponto de vista. O discurso caminha de acordo com a realidade que o autor quer mostrar e de acordo com o seu ponto de vista específico sobre cada questão, aprisionando, dessa forma, o leitor em um ambiente intelectual específico.

Por haver disponíveis poucos trabalhos que aplicam o estudo da pressuposição a corpus de textos, consideramos que este artigo pode contribuir como uma espécie de provocação para suscitar futuras pesquisas.

\section{Referências}

194

CABRAL, Ana Lúcia Tinoco. A força das palavras: dizer e argumentar. São Paulo: Contexto, 2010.

CANÇADO, Márcia. Manual de semântica: noções básicas e exercícios. 2. ed. revisada. Belo Horizonte: Ed. UFMG, 2008

DUCROT, Osvald. Princípios de semântica linguística: dizer e não dizer. São Paulo: Cultrix, 1977.

DUCROT, Osvald. o dizer e o dito. Campinas: Pontes, 1987.

FREGE, Gottlob. Sobre o sentido e a referência. In: Lógica e Filosofia da Linguagem. Seleção, introdução, tradução e notas de Paulo Alcoforado. 2. ed. revista e ampliada. São Paulo: EDUSP, 2009. p. 129-158.

KOCH, Ingedore Grunfield Villaça. Argumentação e linguagem. São Paulo: Cortez, 2008.

LAGE, Nilson. Estrutura da notícia. 6. ed. São Paulo: Ática, 2006.

LEVINSON, Stephen C. Pragmática. São Paulo: Martins Fontes, 2007. .

MOURA, Heronides Maurílio de Melo. Significação e contexto: uma introdução a questões de semântica e pragmática. 3. ed. Florianópolis: Insular, 2006.

MELO, José Marques de. A opinião no jornalismo brasileiro. 2. ed. revista. Petrópolis: Vozes, 1994. 
OLIVEIRA, Iracelane Ferreira da Silva. Pressuposição: da sentença ao texto. 2014. 102 f. Dissertação (Mestrado em Linguística e Ensino) - Universidade Federal da Paraíba, João Pessoa, 2014. Disponível em: <http://tede.biblioteca. ufpb.br:8080/handle/tede/6462>. Acesso em: 23 mar. 2017.

OLÍMPIO, Hilda de Oliveira. Nominalização, memória discursiva e argumentação. SOLETRAS, Ano VI, N 12. São Gonçalo: UERJ, jul./dez.2006. Disponível em: <http://www.e-publicacoes.uerj.br/index.php/soletras/ article/view/4663>. Acesso em: 22 nov. 2017.

SOUZA, Heberth Paulo. A pressuposição linguística na estrutura da língua portuguesa. 2000. 220 f. Dissertação (Mestrado em Língua Portuguesa). PósGraduação em Língua Portuguesa. Pontifícia Universidade Católica de Minas Gerais, Belo Horizonte, 2000. Disponível em: <http://bib.pucminas.br/teses/ Letras_SouzaHP_1.pdf>. Acesso em: 15 ago. 2018. 